\title{
Machine learning applied as an in-situ monitoring technique for the water content in oil recovered by means of NIR spectroscopy
}

DOI: $10.46932 / \mathrm{sfjdv2n1-030}$

Received in: November 1st, 2020

Accepted in: December 30th, 2020

\section{Ayslan S. P. da Costa}

Núcleo de estudos em sistemas coloidais (NUESC) / Instituto de tecnologia e pesquisa (ITP)

Av. Murilo Dantas, 300, Aracaju-SE, Brazil

\section{J Manuela Goncalves}

Núcleo de estudos em sistemas coloidais (NUESC) / Instituto de tecnologia e pesquisa (ITP)

Av. Murilo Dantas, 300, Aracaju-SE, Brazil

\section{Hosana O. Á. Neta}

Núcleo de estudos em sistemas coloidais (NUESC) / Instituto de tecnologia e pesquisa (ITP)

Av. Murilo Dantas, 300, Aracaju-SE, Brazil

\section{Douglas Alves}

Núcleo de estudos em sistemas coloidais (NUESC) / Instituto de tecnologia e pesquisa (ITP)

Av. Murilo Dantas, 300, Aracaju-SE, Brazil

\section{Elton Franceschi}

Núcleo de estudos em sistemas coloidais (NUESC) / Instituto de tecnologia e pesquisa (ITP)

Av. Murilo Dantas, 300, Aracaju-SE, Brazil

Universidade Tiradentes (UNIT), Programa de pós-graduação em Engenharia de Processos (PEP) /

Programas de pós-graduação em Biotecnologia Industrial (PBI)

Av. Murilo Dantas, 300, Aracaju-SE, Brazil,

\section{Claudio Dariva}

Núcleo de estudos em sistemas coloidais (NUESC) / Instituto de tecnologia e pesquisa (ITP)

Av. Murilo Dantas, 300, Aracaju-SE, Brazil

Universidade Tiradentes (UNIT), Programa de pós-graduação em Engenharia de Processos (PEP) /

Programas de pós-graduação em Biotecnologia Industrial (PBI)

Av. Murilo Dantas, 300, Aracaju-SE, Brazil,

\section{Gustavo R. Borges}

Núcleo de estudos em sistemas coloidais (NUESC) / Instituto de tecnologia e pesquisa (ITP)

Av. Murilo Dantas, 300, Aracaju-SE, Brazil

Universidade Tiradentes (UNIT), Programa de pós-graduação em Engenharia de Processos (PEP) /

Programas de pós-graduação em Biotecnologia Industrial (PBI)

Av. Murilo Dantas, 300, Aracaju-SE, Brazil,

\section{Manuela S. Leite}

Universidade Tiradentes (UNIT), Programa de pós-graduação em Engenharia de Processos (PEP) / Programas de pós-graduação em Biotecnologia Industrial (PBI)

Av. Murilo Dantas, 300, Aracaju-SE, Brazil,

E-mail: sl.manuela@gmail.com 


\section{ABSTRACT}

The present work proposes a study on the combination of artificial neural network based model and multivariate calibration techniques, as principais component analysis (PCA) and partial least squares (PLS) combined with near infrared spectrophotometer (NIR) to formulate online water content monitoring models for recovered fuel oils after effluent treatment of a Brazilian thermoelectric plant. The database for adjustments of these models was built using oil samples supplied by the SUAPE II thermoelectric plant, where they were characterized in laboratories and analyzed via NIR. 450 spectra were used to construct the PLS model for predictive model calibration using the PLS technique and 118 spectra for the model based on artificiais neurais networks. In the obtained PLS model, it was possible to obtain correlations around 0.97 , cross-validation error (RMSECV) of 0.0906 and test prediction error (RMSEP) of 0.0651 . The RNA model presented coefficient of determination $\mathrm{R}^{2}$ of 0.99 for training and $\mathrm{R}^{2}$ of 0.98 for test with prediction error of 0.062

Keywords: Artificial neural network, multivariate calibration, NIR and fuel oil.

\section{INTRODUCTION}

Thermoelectric plants are important instruments to guarantee the supply of electricity throughout Brazil. Of these, $15 \%$ use fuel oil to generate electricity. The SUAPE II thermoelectric plant is the second largest plant in the country that uses this type of fuel in its process and consequently produces residual oil. The treatment of the discarded oil allows the recovery of water contained in the oil for internal use and production of fuel oil for commercialization, which promotes cost reduction. The oil treatment is not sold for internal use and the commercialization rate is not updated for commercialization. Due to its complex physicochemical composition, monitoring this oil requires a large number of sensors and complex mathematical models that can require time and a high computational effort.

Heavy Fuel oil is an oil fraction derived from vacuum distillation containing mixtures of hydrocarbons and heteroatom compounds containing (, $\mathrm{N}$ and $\mathrm{O}$ ) and metals. (Elbaz et al., 2015). In the process of energy generation, the fuel oil passes some treatments to remove water, sludge and sediment, before being directed to the engines. These effluents are mixed with all the plant tailings and directed to the treatment units, where the main objective is to treat oily water and recover fuel oil with minimal emulsified water.

In recent years, industries have been undergoing modifications in their form of production, focusing more on intelligent process development, using for example machine learning based techniques for control models. Artificial neural networks (ANN's), one of the dominant techniques in the field of machine learning, is an important branch of artificial intelligence, presenting characteristics of selfadaptation, self-organization and self-learning. (Han et al., 2018, Viana et al., 2018, Veloso et al., 2019, Veloso et al., 2020). Application of ANN-based models for monitoring oil or derivatives may require large numbers of sensors due to the complexity of oil analysis. 
In this sense, the spectroscopic near infrared (NIR) technique, has been studied and applied for analysis in various industry sectors, as it meets critical requirements for this type of application, including rare sample pretreatments and rapid on-line measurement responses (Silva et al., 2019). Connected to the probes via fiber optics, NIR can be an alternative to using sensors for in situ monitoring. In this nondestructive technique, from machine learning based models and multivariate calibration, we obtain various analytic information with a single analysis (Balabin et al., 2010; Rocha and Sheen, 2019).

Due to the need to monitor the percentage of water in recovered fuel oils used in thermoelectric plants, the objective of this study is to evaluate the efficiency in predicting the water content (WC) of residual oil (RO) after centrifugation treatment to control the quality of these oils and to maintain the productive efficiency of the facilities. For this, it was proposed in this work, models based on PLS and artificial feed forward back propagation neural networks to predict water percentages in residual fuel oil. Using as online sensors transflectance probes connected via optical fibers to a near infrared spectrometer.

\section{EXPERIMENTAL SECCION}

The research was conducted with 11 fuel oil samples available from Energética Suape II S.A. These samples were collected at the end of centrifuge treatment and before reuse in the plant or stored in tanks for commercialization.

RO samples were characterized in the laboratory according to water percentage using the Mettler Toledo Karl Fischer DL 39 coulometric titrator. In this equipment, it is possible to measure water percentages between 0 to $5 \%$ with precision of $0.03 \%$. In addition, In order to obtain samples that filled the entire percentage range of water of interest $(0-2 \%)$ were synthesized emulsions, from randomly chosen OR originals. Emulsions were synthesized according to the methodology presented by Fortuny et al. (2007), where the oil was incorporated with the water, initially manually, at previously defined concentrations $(0.62,0.86,1.38,1.68,1.97)$. The pre-emulsified system was then subjected to the UltraTurrax T-25 Basic - IKA homogenizer at a speed of $9500 \mathrm{rpm} \cdot \mathrm{min}^{-1}$ for 1:30 minutes to obtain stable emulsions. (Fortuny et al., 2007; Araújo et al., 2008).

The NIR spectra were obtained by a spectrophotometer (MPA, Bruker) using a transflectance probe with optical path length adjusted in $1 \mathrm{~mm}$. The sample was inserted in into a jacketed glass cell coupled to the thermostatic bath for temperature control. The spectra were collected in NIR region (4000 to $12000 \mathrm{~cm}^{-1}$ ) with 16 scans to form a spectrum with a resolution of $8 \mathrm{~cm}^{-1}$. The absorbance peaks, referring to combinations and overlaps of molecular vibrations of carbon and hydrogen, are used in predict models of the properties of interest. 
The database was built with 450 spectra for predictive model calibration using the PLS technique available in the OPUS software that accompanies the spectrophotometer. Among the obtained spectra, about 25 to $30 \%$ were used for model tests. The spectra are then subjected to pretreatment, where the 5450 - $4246.6 \mathrm{~cm}-1$ spectral region was selected to adjust the models, and then the Savitzky-Golay first derivative technique was applied using the 3-way smoothing method points.

The region selection was made according to the water molecule interaction region and through the optimization processor also available in OPUS software as the best region for such correlation. The derivative method calculates a rate of change of signal variation in relation to the wavelength. As a result, the techniques emphasize the bands and the absorbance peaks, which correspond to the analyte characteristic. Thus, it is intended to obtain a spectrum that may be easier for evaluation (CONZEN, 2014).

For neural network based development, the spectra were represented by a 1 x 113 vector where the matrix column number represents the wavelength between 5450 to $4246.6 \mathrm{~cm}-1$, resulting in 118 spectra divided into two distinct sets, one for model training and one for model testing (Moreira 2015). PCA was used to select the number of minimum components that represented the maximum variation explained from the original data set. These components were normalized according to equation 1 within a range of -1 to 1 and used as input variables for the neural model.

$$
z_{n}=\frac{\left(z_{\max }-z_{\min }\right)\left(x_{i}-x_{\min }\right)}{x_{\max }-x_{\min }}+z_{\min }
$$

Where, $z_{n}$ are the normalized data, $x_{\max }$ and $x_{\min }$ are the maximum and minimum data values for raw data, $x_{i}$ is the raw data point, $z_{\max }$ and $z_{\min }$ are the maximum and minimum normalized data.

The model was developed in MATLAB version 2016, being set with a hidden layer, defining the amount of neuron in this layer defined by the smallest error generated. For network training, the Levemberg-Marquardt algorithms and Bayesian regularization were tested.

To evaluate the predictive capacity of the proposed models, 3 statistical tools were used: mean square error (MSE), presented in equation 1, to optimize the parameter adjustment and, consequently, the error generated in the model training step. The root mean square error (RMSE), described in equation 2 was used in the cross-validation steps of the PLS model and testing of both models. In addition, the coefficient of determination $\left(\mathrm{R}^{2}\right)$ was evaluated in both stages (training and tests). 


$$
\begin{gathered}
M S E=\frac{1}{M} \cdot \sum_{1}^{M}\left(Y_{i}^{\text {exp }}-Y_{i}^{\text {pred }}\right) \\
R M S E=\sqrt{M S E}
\end{gathered}
$$

Eq. 2

For better understanding, equation 2, when used for the PLS model, was presented in the following topic as RMSECV to show the cross validation error at the time of model fit and RMSEP to elucidate the prediction error in the testing step. For the neural network based model, the RMSE presented in the present study refers to the test stage.

\section{RESULTS AND DISCUSSION}

Table 1 shows the water content of the 11 recovered oil samples and the 5 synthesized emulsion samples in the laboratory.

Figure 1. Experimental value of water content for residual oil sample (A) after treatment and and synthesized samples (B) with their respective experimental error.

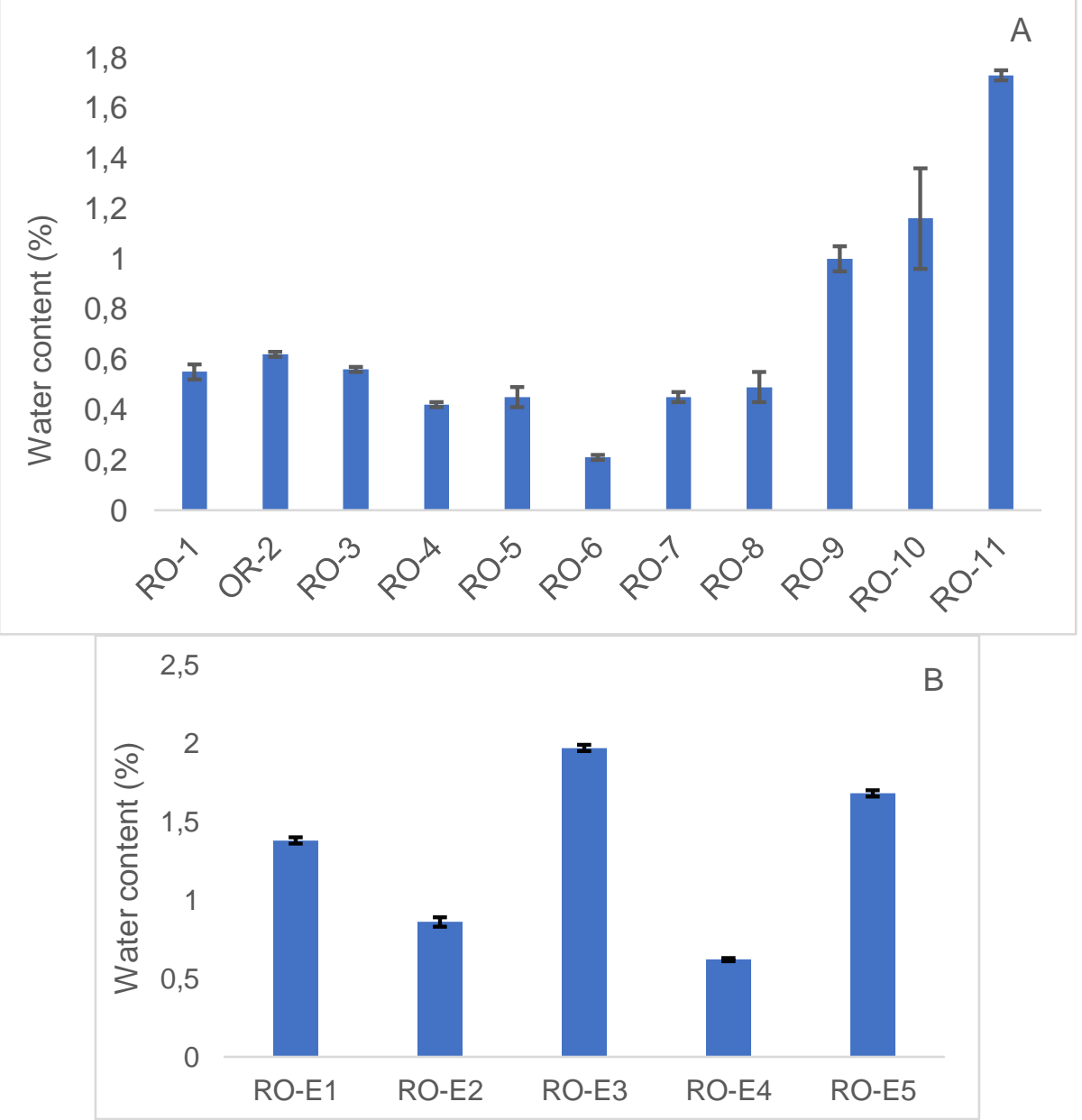


It is possible to identify in Figure 1 that most of the samples presented AT less than $1 \%$, indicating good performance in the water removal process in the treatment of effluents generated in the plant. In addition, it is clear the need to synthesize emulsions in the laboratory from samples obtained by industry, as there is a need to monitor the percentage of water in the range of 0 to $2 \%$. It is noticeable that the analyzes were reliable with an average error of 0.03 , due to the low errors found in triplicate tests These results were added to the respective spectra to compose the data set for chemometric model adjustments.

After characterization, the spectra of the respective oils and the aforementioned emulsions were collected, with temperatures ranging from 85 to $100{ }^{\circ} \mathrm{C}$. Given that, the operating temperature where the infrared probe will be installed has an average temperature of 90 to $95^{\circ} \mathrm{C}$. Figure 2 shows the near infrared spectra, with a temperature of 85 to $100{ }^{\circ} \mathrm{C}$ for a single randomly chosen sample, with the objective of exemplifying the spectra profile of the oils.

Figura 2. NIR spectra for sample OR-5 with temperature ranging from 85 to $100^{\circ} \mathrm{C}$.

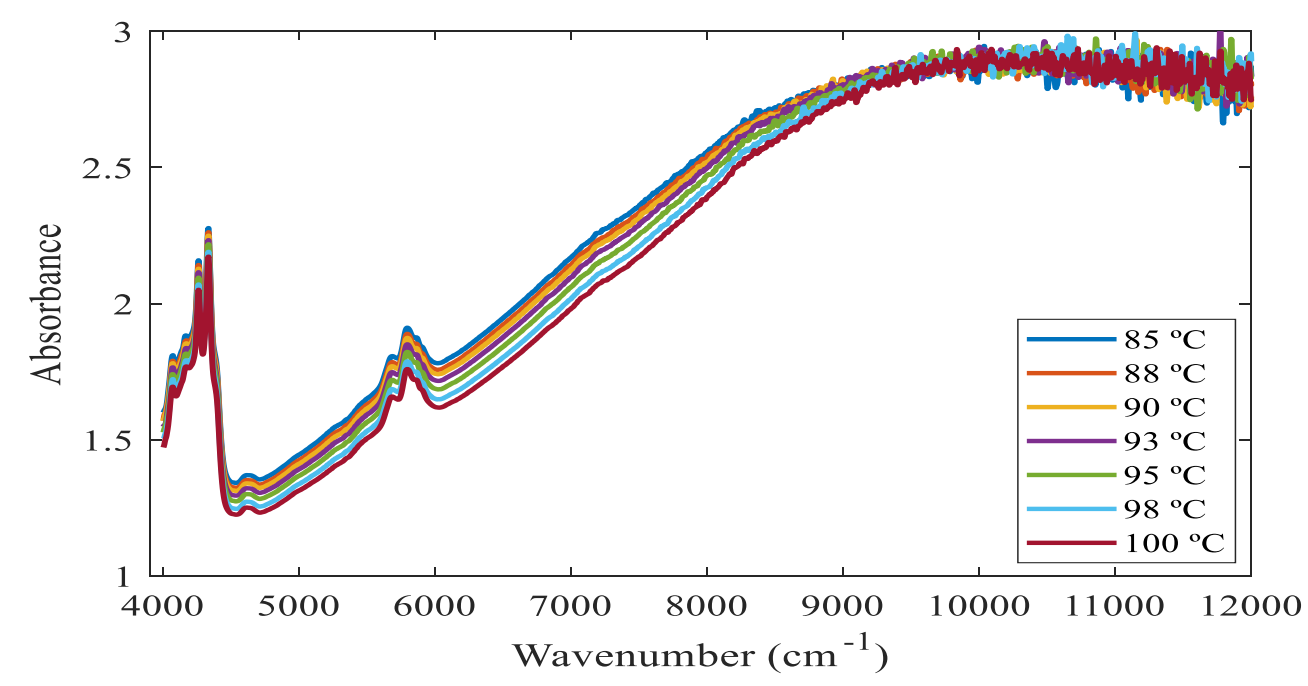

The absorbance bands found in Figure 2 come mainly from the vibrations of $\mathrm{C}-\mathrm{H}$ groups, may be associated with flexions of $\mathrm{CH} 2$ and $\mathrm{CH} 3$ chemical bonds. In addition, the region between 5500 and 6000 $\mathrm{cm}-1$ represents the first harmonic of the fundamental elongation $\mathrm{C}-\mathrm{H}$, corresponding to the methyl, methylene and ethylene groups (Laxalde et al., 2014). Regardless of RO or synthesized emulsions, the spectra structures do not change. The main variance found in the spectrum set is the change in absorbance values with increasing temperature.

The spectral signal presented in Figure 2 was used to adjust the proposed models for water percentage prediction. Thus, to construct a more accurate model, a spectrum fragment equivalent to the region between 5450 - $4246.6 \mathrm{~cm}-1$ was selected and the first derivative applied as spectrum pretreatment. This wavelength may be more appropriate because the literature shows that the water 
concentration of an analytic can be correlated with hydroxyl group vibrations corresponding to wavelengths around $5200 \mathrm{~cm}^{-1}$. In addition, a smaller selected region facilitates the interpretation of spectra, enabling better correlations. (Araújo et al., 2008; Moreira et al., 2015; Aparício et al., 2016).

Initially a PLS model was fitted to the NIR spectra to predict the percentage of water present in the oils. For this development, 450 spectra were used for calibration and 92 spectra for testing (approximately $17 \%$ of the spectrum set) in a temperature range of 88 to $100^{\circ} \mathrm{C}$. Figure 2 shows the correlation graph obtained in the calibration and testing steps of this model.

Figure 3. Predicted vs experimental values for cross-validation (O) and test (+) for PLS model.

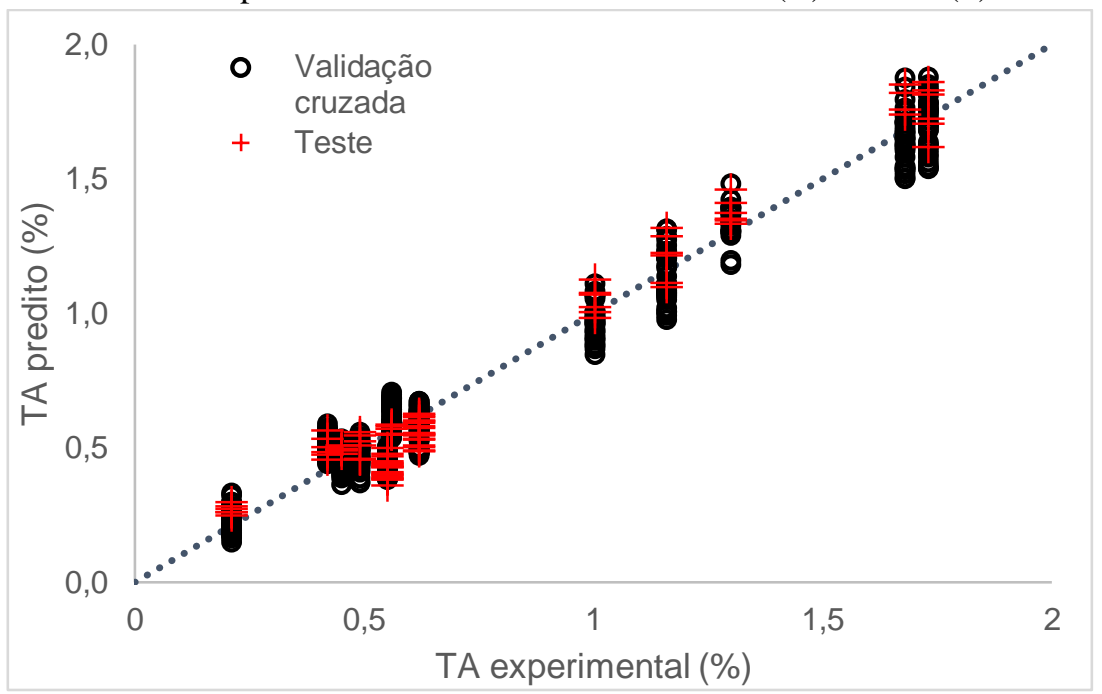

As can be seen from the cross-validation and prediction test results presented in Figure 2, the robust database spanning much of the $0-2 \%$ range was able to generate a model with good predictive ability of water content data. In both analyzes, correction factor values were greater than 0.97 . Crossvalidation generated an RMSECV of 0.0906 and the prediction test generated an RMSEP of 0.0651 .

These statistical parameters show that the model can well predict the water content values for recovered oil samples for recovered oil samples in the 0 to $2 \%$ range using the $1 \mathrm{~mm}$ optical path probe.

The next step was to propose a model based on artificial neural networks, in order to verify the possibility of reducing the prediction error and, consequently, to obtain a more robust model to monitor the water percentage of oils after treatment. For this, the absorbance values referring to the NIR spectra were submitted to PCA, with the objective of dimensionality reduction the same spectra used to adjust the PLS models were used for neural model training, except for the use of its replicas. In addition, the model's spectral adjustment region and pretreatment were also maintained using the first derivative, highlighting the information contained in the spectra and eliminating possible noise (Long et al., 2019). 
Figura 4. Percentage variation explained in relation to the number of main componentes

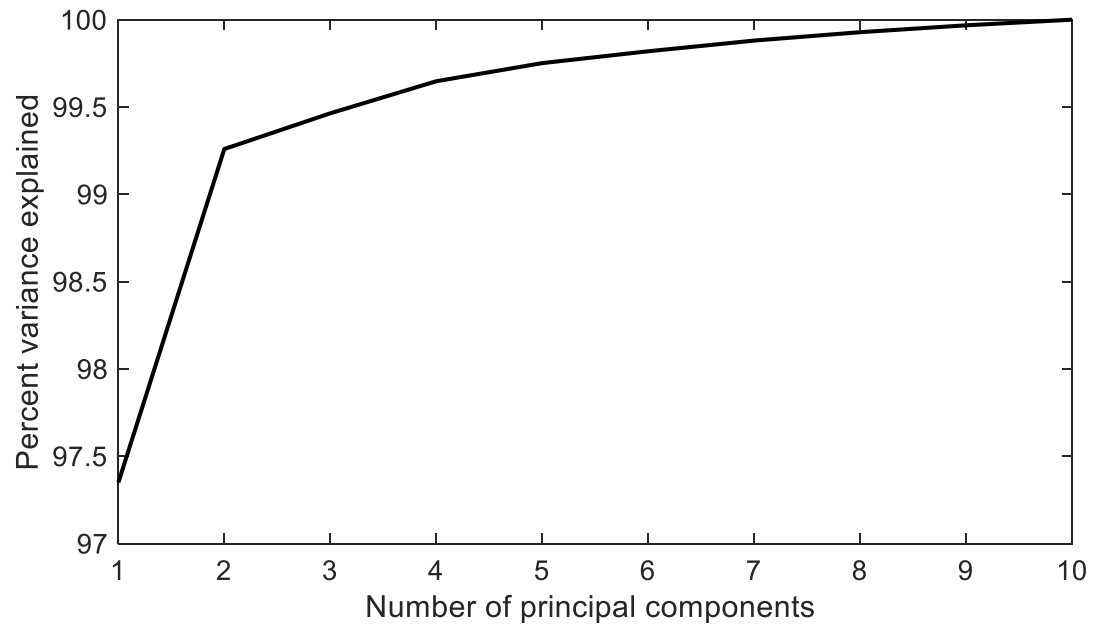

Figure 4 shows that with 2 components it is already possible to obtain a data set representing more than $99 \%$ of the variation presented in the original data set. Thus, 4 components (about 99.6\%) were used as input variables for the development of the neural model.

An important step in configuring the neural model prior to your training is defining the number of neurons in the hidden layer. Studies show that there is no specific methodology for this procedure, leaving this definition submitted to a trial and error process. (SURYAWANSHI AND MOHANTY 2018).

Figura 5. Correlation between neuron number and RMSE

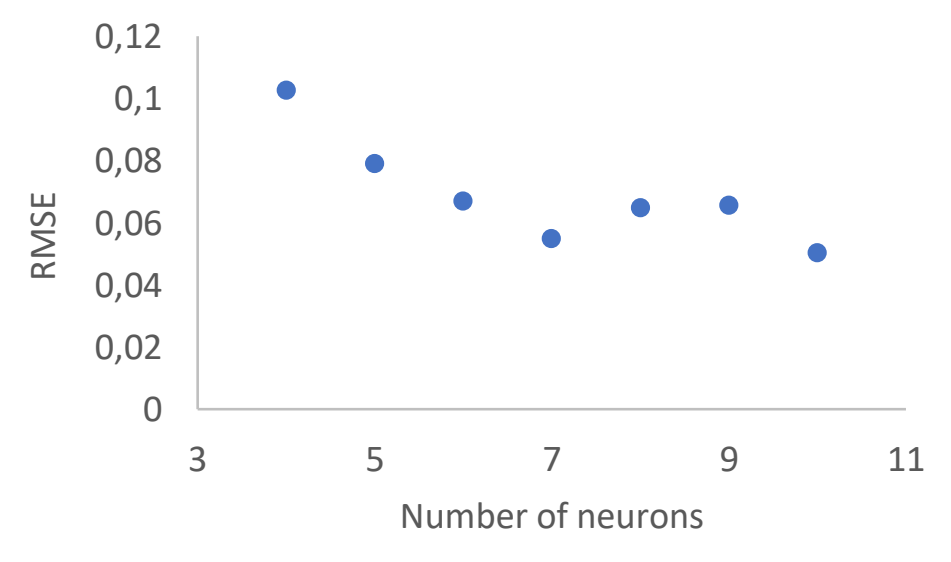

Figure 5 shows that up to 7 neurons the RMSE value decreases linearly to the error of 0.055 , but the error tends to increase when the neuron number exceeds 8 and decreases again when 10 neurons is 
selected $(\mathrm{RMSE}=0.05)$. Thus, it was proposed that using 7 neurons would be more suitable for the final configuration of the model.

The regression graphs obtained in the training and testing stages of the 4-7-1 architecture model are presented in Figure 6.

Figure 6. Regression graph in the training stage of model (A) and test (B).
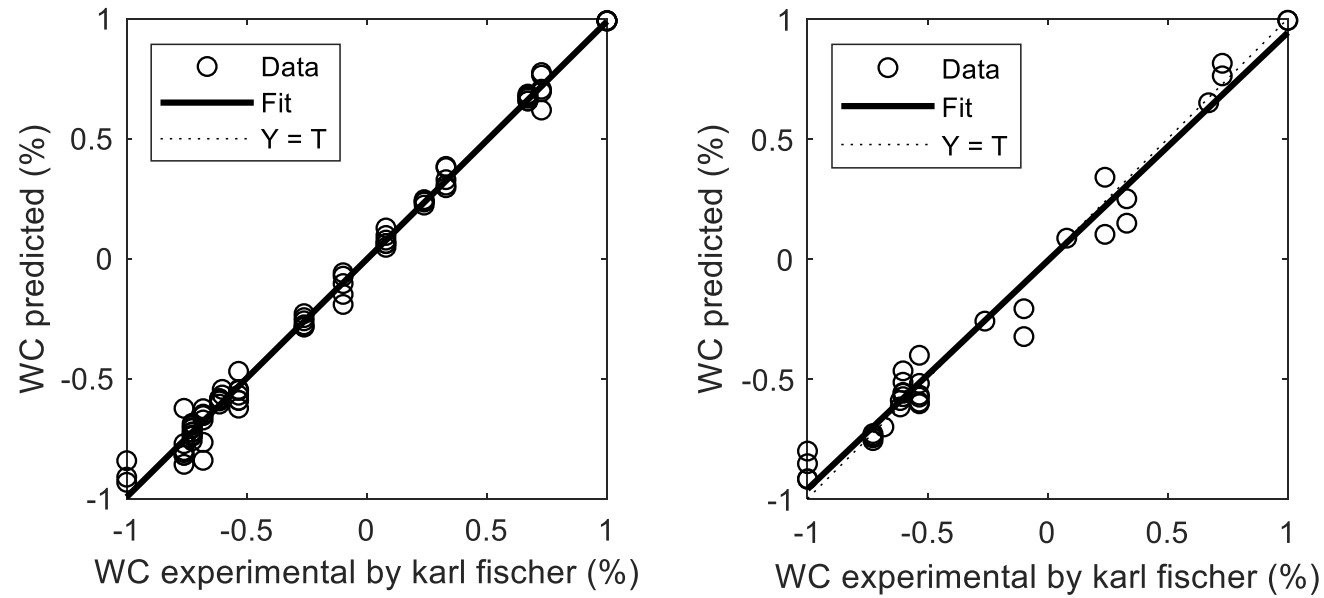

The Figure 6 shows the good correlations obtained between the data predicted by the model and the reference values, reaching an $\mathrm{R}^{2}$ of 0.99 for the training stage and 0.988 for the test data. It is noteworthy that the data directed to the model test are different from those used to adjust the model.

Considering the results obtained in Figure 6, it is evident that the model proposed by RNA is adequate to correlate the spectral signal obtained by NIR with the percentage of water present in the recovered fuel oil.

\section{CONCLUSIONS}

Machine learning model, more specifically artificial neural networks, and PLS were adjusted using spectra obtained from NIR analysis for water content monitoring. The NIR was connected to a probe by fiber optics for use in the industrial line, and thus, together with the models, compose an on-line monitoring system for fuel oil treated in the SUAPE II thermoelectric power plant.

The proposed models proved to be able to predict, with good accuracy, the water content of the samples in a range of 0 to $2 \%$ within an operating temperature range of 85 to $100{ }^{\circ} \mathrm{C}$. Given that the industry standard temperature is around 90 to $95^{\circ} \mathrm{C}$.

The PLS model presented RMSECV of 0.0906 and RMSEP of 0.0651 with determination coefficients of 0.97, whereas the RNA-based model presented RMSE close to PLS in the test stage, but the resulting determination coefficient in the determination stages. Training and testing were superior $(0.99$ and 0.98 
respectively). Showing that the RNA model is more accurate at predicting values within the error than the PLS model. Thus, it is concluded in this study that NIR spectroscopy plus the RNA model is the most suitable for on-line monitoring of water content in the SUAPE II thermoelectric power plant.

\section{ACKNOWLEDGEMENT}

The authors gratefully acknowledge the financial support from: Brazilian Foundation of the Ministry of Education (CAPES, Coordenação de Aperfeiçoamento de Pessoal de Nível Superior (financing code 001)); the National Council for Scientific and Technological Development (CNPq, Conselho Nacional de Desenvolvimento Científico e Tecnológico), Process: 420717/2018-8; Support Foundation for Research and Technological Innovation of the State of Sergipe (FAPITEC, Fundação de Apoio à Pesquisa e a Inovação Tecnológica do Estado de Sergipe), Energetica Suape II S.A. linked to the Research and' Development Program of the National Electric Energy Agency

- ANEEL. Brazil. 


\section{REFERENCES}

Aparicio, C.; Guerrero, J.; Cabanzo, R.; Mejía-ospino, E. Bromine, "Number Prediction for Colombian Naphthas Using Near-Infrared Spectroscopy and Chemometric Methods”, Rev. ion, 29 (2), 75-85, (2016)

Araujo, A. M.; Santos, 1. M.; Fortuny, M.; Melo, R. L. F. V; Coutinho, R. C. C.; Santos, A. F, "Evaluation of Water Content and Average Droplet Size in Water-in-Crude Oil Emulsions by Means of Near-Infrared “, Energy Fuels, 4, 3450-3458, (2008)

Balabin, R. M. Safieva, R. Z. Lomakina E. I, "Gasoline classification using near infrared (NIR) spectroscopy data: Comparison of multivariate techniques" Analytica Chimica Acta 671 (2010) 27-35 BIG, Banco de Informações de Geração. Acesso em 04 de Abril de 2019, available in: http://www2.aneel.gov.br/aplicacoes/capacidadebrasil/capacidadebrasil.cfm

Conzen, J. P. "Multivariate calibration: A practical guide for the method development in the analytical chemistry". 3rt ed. Bruker, ISBN 3-929431-13-3, (2014)

Elbaz, A. M.; Gani, A.; Hourani, N.; Emwas, A.; Sarathy, S. M.; Roberts, W. L. "TG/DTG, FT-ICR Mass Spectrometry, and NMR Spectroscopy Study of Heavy Fuel Oil”. Energy Fuels, 29, 7825. (2015).

Han, Y. Zeng, Q. Geng, Z. Zhu, Q. "Energy management and optimization modeling based on a novel fuzzy extreme learning machine: Case study of complex petrochemical industries" Energy Conversion and Management 165 163-171, (2018)

Laxalde, J.; Caillol, N.; Wahl, F.; Ruckebusch, C.; Duponchel, L. "Combining near and Mid Infrared Spectroscopy for Heavy Oil Characterisation". Fuel, 133, 310-316, (2014).

Long, J. Wang, K. Yang, M. and Zhong W.,"Rapid crude oil analysis using near-infrared reflectance spectroscopy", Petroleum Science and Technology, DOI: 10.1080/10916466.2018.1547754

Fortuny M, Oliveira, C. B. Z. Melo,R. L. F, Coutinho, R. C. C., Santos, A. F. "Effect of Salinity, Temperature, Water Content, and $\mathrm{pH}$ on the Microwave Demulsification of Crude Oil Emulsions" Energy and Fuels. 21 1358-1364, (2007)

Silva, N. C. Massa, A. R. C. G Domingos, D. Amigo, J M Rebouças, M. V. Pasquini, C. Pimentel, M F. "NIR-based octane rating simulator for use in gasoline compounding processes", Fuel, 243 381-389, (2019)

Moreira, S. A.; Sarraguça, J.; Saraiva, D. F.; Carvalho, R.; Lopes, J. A. “Optimization of NIR Spectroscopy Based PLSR Models for Critical Properties of Vegetable Oils Used in Biodiesel Production”. Fuel, (2015).

Rocha, W. F. C. Sheen, D. A. "Determination of physicochemical properties of petroleum derivatives and biodiesel using GC/MS and chemometric methods with uncertainty estimation" Fuel 243, 413-422 (2019)

Suryawanshi, B. Mohanty, B. "Application of an artificial neural network model for the supercritical fluid extraction of seed oil from Argemone mexicana (L.) seeds", Industrial Crops and Products, 123, 64-74 (2018).

Veloso, Y. M. S., Almeida, M.M., Alsina, O. L. S., Leite, M. S. "Artificial neural network model for the flow regime recognition in the drying of guava pieces in the spouted bed", Chemical Engineering 
Communication, 1-10, (2019) doi:10.1080/00986445.2019.1608192

Veloso, Y. M. S, Almeida, M. M., Alsina, O. L. S., Passos, M. L., Mujumdar, A. S., Leite, M. S. "Hybrid phenomenological/ANN-PSO modelling of a deformable material in spouted bed drying process", Powder Technology, 366,185 - 196 (2020).

Viana, D. F., Salazar-Banda, G. R., Leite, M. S. "Electrochemical degradation of reactive black 5 with surface response and artificial neural networks optimization models", Separation Science Technology, 53, 2647-2661, (2018). 